Original Article

\title{
Hubungan Obesitas dengan Kejadian Hipertensi pada Perempuan Minangkabau
}

\author{
Relationship of Obesity with Hypertension Minangkabau Women \\ Naufal Jihad Alfalah ${ }^{1}$, Dita Hasni*1, Nilas Warlem ${ }^{1}$, Budi Yulhasfi Febrianto ${ }^{1}$ \\ ${ }^{1}$ Fakultas Kedokteran, Universitas Baiturrahmah, Padang, Indonesia, \\ (ditahasni@fk.unbrah.ac.id/ 085288689988)
}

\begin{abstract}
ABSTRAK
Penelitian ini bertujuan untuk mengetahui hubungan obesitas dengan kejadian hipertensi pada perempuan etnis Minangkabau. Penelitian case control ini dilaksanakan di Puskesmas Anak Air Kota Padang dan mengikutsertakan 40 orang perempuan etnis Minangkabau dengan hipertensi dan 40 orang tanpa hipertensi. Subjek diikutsertakan setelah memenuhi kriteria inklusi dan eksklusi penelitian dan menandatangani inform concent. Hasil penelitian yaitu perempuan etnis Minangkabau yang mengalami obesitas dengan kejadian hipertensi sebanyak 29 orang $(85,3 \%)$ dan yang tidak mengalami hipertensi sebanyak 5 orang $(14,70 \%)$. Sedangkan untuk perempuan etnis Minangkabau yang tidak obesitas mengalami kejadian hipertensi sebanyak 11 orang $(23,1 \%)$ dan yang tidak mengalami hipertensi sebanyak 35 orang $(76,1 \%)$. Terdapat hubungan antara obesitas dengan kejadian hipertensi pada perempuan etnis Minangkabau, hal ini didasarkan pada perolehan $p$ value sebesar 0,000. Kesimpulan yaitu status obesitas memiliki hubungan dengan kejadian hipertensi pada perempuan etnis Minangkabau. Perempuan etnis Minangkabau yang mengalami kejadian hipertensi rata-rata IMT sebesar $32,82 \mathrm{Kg} / \mathrm{m}^{2}$
\end{abstract}

Kata kunci : Hipertensi, Minangkabau, Obesitas, Perempuan

\section{ABSTRACT}

This study aims to determine the relationship between obesity and the incidence of hypertension in Minangkabau ethnic women. This case control study was conducted at the Children's Water Health Center in Padang City and included 40 ethnic Minangkabau women with hypertension and 40 people without hypertension. Subjects were included after meeting the inclusion and exclusion criteria of the study and signing the informed consent. The results of the study were that there were 29 Minangkabau ethnic women who were obese with hypertension incidence (85.3\%) and 5 people (14.70\%). As for the Minangkabau ethnic women who were not obese, 11 people (23.1\%) experienced hypertension and 35 people (76.1\%). There is a relationship between obesity and the incidence of hypertension in Minangkabau ethnic women, this is based on the acquisition of a $p$ value of 0.000. The conclusion is that obesity status has a relationship with the incidence of hypertension in Minangkabau ethnic women. Minangkabau ethnic women who experience hypertension have an average BMI of $32.82 \mathrm{Kg} / \mathrm{m} 2$.

Keywords : Hypertension, Minangkabau, Obesity, Woman

https://doi.org/10.33860/jik.v15i4.823

(C) 2021 by the authors. Submitted for possible open access publication under the terms and conditions of the Creative

Commons Attribution (CC BY SA) license (https://creativecommons.org/licenses/by-sa/4.0/). 


\section{PENDAHULUAN}

Hipertensi berdasarkan data World Health Organization (WHO) diderita oleh 22\% dari total seluruh penduduk di belahan dunia. ${ }^{1}$ Data Riset Kesehatan Dasar (RISKESDAS) tahun 2018 melaporkan, bahwa tercatat kasus hipertensi diderita oleh $34 \%$ penduduk Indonesia. $^{2}$ di Provinsi Sumatera Barat dilaporkan terdapat $25,16 \%$ penderita hipertensi pada tahun 2018. ${ }^{2}$ Berdasarkan laporan dari seluruh Puskesmas di kota Padang pada tahun 2016 hipertensi mencapai peringkat lima penyakit yang sering diderita penduduk kota Padang dan menyebabkan tingkat mortalitas sebanyak 32 orang atau sekitar $8,72 \% .^{3}$

Salah satu faktor risiko hipertensi adalah obesitas. Prevalensi kejadian obesitas pada dewasa di indonesia mencapai $11,7 \%$. Angka prevalensi obesitas berdasarkan jenis kelamin di Sumatera Barat untuk jenis kelamin wanita mencapai $38 \%$ dan untuk pria mencapai $27 \%$ yang mana prevalensi obesitas pada wanita lebih tinggi dibandingkan dengan pria di Provinsi Sumatera Barat. ${ }^{2}$

Terdapat dua cara obesitas menyebabkan terjadinya hipertensi, yaitu dengan direct dan indirect. secara direct yaitu seseorang mengalami obesitas pasti orang tersebut memiliki IMT yang melebihi normal sehingga pasokan darah atau cardiac output meningkat. Sedangkan secara indirect melalui stimulasi aktivitas renin angiotensin aldosteron system (RAAS) yang memiliki relasi erat dengan retensi cairan dan $\mathrm{Na}$ sehingga stroke volume bertambah dan juga aktivitas simpatis yang berkaitan dengan peningkatan denyut nadi dan vasokontriksi. ${ }^{4,5}$

Prevalensi hipertensi yang diikuti dengan obesitas sering direlasikan oleh usia, jenis kelamin, dan budaya. Berdasarkan penelitian oleh Lipoeto dkk menunjukkan secara umum pasien yang mengalami Sindrom metabolik yang fokusnya pada hipertensi dan obesitas dengan indikator jenis kelamin kejadiannya lebih banyak pada perempuan sebanyak $26,8 \%$ dan hanya $6,3 \%$ pada pasien laki-laki. ${ }^{6}$

Data Dinas Kesehatan (DINKES) Kota Padang untuk kasus hipertensi tahun 2017, usia 45-55 tahun ada sekitar 1.149 kasus pada lakilaki sedangkan pada perempuan ada sekitar 2.974 kasus sehingga jumah kasus hipertensi perempuan lebih dominan dari pada laki-laki. ${ }^{7}$ Penderita hipertensi banyak terjadi pada lanjut usia (lansia), namun tidak menutup kemungkinan pada usia produktif (15-64 tahun) bisa mengalami hipertensi. ${ }^{8}$

Sangadji dan Nurhayati melaporkan berdasarkan penelitian mereka, responden dengan suku Minangkabau mempunyai risiko tinggi terkena hipertensi dan obesitas yang berkaitan dengan kebiasaan makan dan pemilihan jenis makanan dibandingkan dengan suku lainnya di Indonesia. ${ }^{9}$

Budaya Minangkabau terkenal dengan makanannya. Keistimewaaan cita rasa masakan suku Minangkabau memiliki rasa pedas dan penggunaan santan yang kental. Cara pengolahan makanan yang dilakukan oleh suku Minangkabau secara umum lebih sering menggunakan bumbu dan garam yang dapat menjadi faktor risiko hipertensi dan obesitas. ${ }^{10,11}$ Kebiasaan lainnya yang mendorong meningkatnya prevalensi hipertensi yaitu kurangnya mengkonsumsi sayuran, kurangnya aktivitas fisik, dan kebiasaan merokok. ${ }^{12}$

Berdasarkan latar belakang masalah di atas, penulis tertarik untuk melakukan penelitan tentang hubungan obesitas dengan kejadian hipertensi pada perempuan etnis Minangkabau.

\section{METODE PENELITIAN}

Penelitian case control ini dilaksanakan di Puskesmas Anak Air Kota Padang pada bulan Maret sampai November 2021, setelah disetujui komite etik Fakultas kedokteran Universitas Baiturrahmah dengan No. 089/ETIKFKUNBRAH/03/07/2021. Penelitian ini menggunakan teknik purposive sampling yaitu sampel yang diikutsertakan dengan kriteria inklusi dan eksklusi penelitian., yaitu perempuan, berusia 18-45 tahun, etnis minangkabau ( ibu dan nenek memiliki etnis minangkabau), tidak hamil, tidak menyusui, menderita hipertensi untuk kelompok kasus dan tidak menderita hipertensi untuk kelompok kontrol. Pada penelitian ini terdapat 40 subjek kasus dan 40 subjek kontrol yang bersedia ikut serta dan telah menandatangani inform concent. Pengambilan data tetap mematuhi protokol kesehatan covid 19, proses dokumentasi data menggunakan form online. Analisis data menggunakan uji chi square dengan tingkat signifikansi $\mathrm{p}<0,05$.

\section{HASIL}

Berdasarkan penelitian yang telah dilakukan untuk mengetahui hubungan obesitas dengan kejadian hipertensi pada perempuan 
etnis Minangkabau, maka dapat dilihat pada tabel 1 .

Tabel 1. Hubungan Obesitas dengan Hipertensi Pada perempuan etnis Minangkabau

\begin{tabular}{|c|c|c|c|c|c|}
\hline \multirow{3}{*}{ Obesitas } & \multicolumn{4}{|c|}{ Hipertensi } & \multirow{3}{*}{$P$ value } \\
\hline & \multicolumn{2}{|c|}{ ya } & \multicolumn{2}{|c|}{ Tidak } & \\
\hline & $\mathbf{n}$ & $\%$ & & $\%$ & \\
\hline $\mathrm{Ya}$ & 29 & 85.3 & 5 & 14.7 & \multirow{3}{*}{0.000} \\
\hline Tidak & 11 & 23.9 & 35 & 76.1 & \\
\hline Total & & & & & \\
\hline
\end{tabular}

Tabel 2. Gambaran Rerata IMT Perempuan Etnis Minangkabau

\begin{tabular}{cc}
\hline Kelompok & BMI (mean \pm SD) \\
\hline Hipertensi & $32,82 \pm 5,86$ \\
Tidak hipertensi & $24,72 \pm 3,95$ \\
\hline
\end{tabular}

Berdasarkan tabel 1 diketahui jumlah sampel dengan obesitas yang mengalami hipertensi sebanyak 29 orang $(85,3 \%)$, untuk sampel obesitas yang tidak mengalami hipertensi sebanyak 5 orang $(14,70 \%)$. Sedangkan jumlah sampel tidak obesitas yang mengalami hipertensi sebanyak 11 orang $(23,1 \%)$, untuk sampel tidak obesitas yang tidak mengalami hipertensi sebanyak 35 orang $(76,1 \%)$.

Analisa statistik menggunakan chi square diperoleh nilai $p$ dari hubungan obesitas dengan kejadian hipertensi pada perempuan etnis Minangkabau sebesar 0,000. Berdasarkan pertimbangan yang telah di tetapkan bahwa hubungan dikatakan bermakna apabila $\mathrm{P}<0,05$. Sehingga secara statistic dapat disimpulkan bahwa terdapat hubungan obesitas dengan kejadian hipertensi pada perempuan etnis Minangkabau.

Berdasarkan tabel 2 dapat diketahui gambaran rerata IMT dari perempuan etnis Minangkabau yang mengalami kejadian hipertensi rata-rata IMT sebesar $32,82 \mathrm{Kg} / \mathrm{m}^{2}$. Sedangkan untuk perempuan etnis Minangkabau yang tidak mengalami kejadian hipertensi rata-rata IMT sebesar $24,72 \mathrm{Kg} / \mathrm{m}^{2}$.

\section{PEMBAHASAN}

Hasil penelitian ini menunjukkan bahwa perempuan etnis Minangkabau yang mengalami obesitas dengan kejadian hipertensi sebanyak 29 orang $(85,3 \%)$ dan tidak mengalami hipertensi sebanyak 5 orang $(14,70 \%)$ Sedangkan untuk perempuan etnis Minangkabau yang tidak obesitas mengalami kejadian hipertensi sebanyak 11 orang $(23,1 \%)$ dan yang tidak mengalami hipertensi sebanyak 35 orang $(76,1 \%)$. Dan secara statistic diperoleh adanya hubungan, Hal ini sesuai dengan penelitian sebelumnya yang dilakukan oleh Sulastri yang menyatakan bahwa proporsi kejadian hipertensi lebih banyak pada responden yang mengalami obesitas sebesar 64 $(56,6 \%)$ orang dibandingkan dengan responden yang tidak mengalami obesitas $38(41,8 \%)$ orang. Hasil uji statistik diperoleh p-value $=0$, 049 yang berarti $p<\alpha(0,05)$, maka dapat disimpulkan bahwa terdapat hubungan obesitas dengan kejadian hipertensi pada masyarakat Etnis Minangkabau di Kota Padang Tahun 2015, dengan nilai OR 2,72 artinya responden dengan obesitas memiliki peluang 2,72 kali mengalami hipertensi apabila dibandingkan dengan responden tidak obesitas. ${ }^{13}$

Penelitian ini juga sesuai dengan penelitian oleh Putri yang menunjukkan bahwa proporsi kejadian hipertensi lebih banyak pada responden yang mengalami obesitas sebesar 30 $(83,3 \%)$ orang dibandingkan dengan responden yang tidak mengalami obesitas $25(43,1 \%)$ orang. Hasil uji statistik diperoleh p-value $=0$, 003 yang berarti $p<\alpha(0,05)$, maka dapat disimpulkan bahwa terdapat hubungan obesitas dengan kejadian hipertensi usia dewasa muda di wilayah Puskesmas Sumbersari Kota Metro Tahun 2020, dengan nilai OR 6,600 artinya responden dengan obesitas memiliki peluang 6,6 kali mengalami hipertensi apabila dibandingkan dengan responden tidak obesitas. ${ }^{14}$

Penelitian lain yang dilakukan oleh Solihati dan Ruswanti bahwa terdapat 
hubungan bermakna antara berat badan dan kejadian hipertensi, hal ini dibuktikan Nilai Odds ratio sebesar 4,881 berarti mahasiswa obesitas memilki kecenderungan untuk terkena hipertensi sebesar 4,881 atau 5 kali lebih besar dibandingkan dengan mahasiswa dengan berat badan normal.Hal ini berarti bahwa obesitas merupakan factor risiko untuk terjadinya hipertensi, Penderita obesitas mempunyai risiko mengalami hipertensi lebih besar dibandingkan subjek yang mempunyai IMT normal. ${ }^{15}$ Hasil penelitian yang dilakukan oleh Natalia ddk yang dilakukan di Kecamatan Sintang, Kalimantan Barat pada tahun 2015, menunjukkan ada hubungan yang signifikan antara obesitas dengan kejadian hipertensi, nilai $\mathrm{p}$ value yang diperoleh sebesar $0,001 .^{16}$

Hasil penelitian menunjukan perempuan etnis Minangkabau yang mengalami kejadian hipertensi rata-rata IMT sebesar $32,82 \mathrm{Kg} / \mathrm{m} 2$. Sedangkan untuk perempuan etnis Minangkabau yang tidak mengalami kejadian hipertensi rata-rata IMT sebesar $24,72 \mathrm{Kg} / \mathrm{m} 2$.

Hasil penelitian ini sesuai dengan penelitian sebelumnya, penelitian dari Sulastri dkk pada tahun 2015 yang melaporkan bahwa rata rata BMI pada perempuan etnis Minangkabau pengidap hipertensi lebih tinggi dibandingkan dengan rata rata BMI pada perempuan etnis Minangkabau yang tidak hipertensi. ${ }^{13}$ Penelitian ini juga sesuai dari penelitian Gusni (2018) meneliti di wilayah kerja Puskesmas Belimbing Kota Padang menemukan bahwa rata rata BMI pada masyarakat etnis Minangkabau pengidap hipertensi lebih tinggi dibandingkan dengan rata rata BMI pada masyarakat etnis Minangkabau yang tidak hipertensi. ${ }^{17}$

Prevalensi kejadian obesitas dan overweight juga mengalami kenaikan di seluruh dunia tepatnya di Asia yang disebabkan perubahan life style dan pengaruh kemajuan teknologi. ${ }^{18}$ Kejadian obesitas di Indonesia termasuk dengan prevalensi yang tinggi . Prevalensi kejadian obesitas pada dewasa di indonesia mencapai $11,7 \%$. Angka prevalensi obesitas berdasarkan jenis kelamin pada Sumatera Barat untuk jenis kelamin wanita mecapai $38 \%$ dan untuk pria mencapai $27 \%$ yang mana prevalensi obesitas pada wanita lebih tinggi dibandingkan dengan pria di Provinsi Sumatera Barat. ${ }^{19}$

Patogenesis obesitas dapat menjadi hipertensi bisa melalui beberapa mekanisme, satu diantara nya adalah obesitas memicu hiperinsulinemia.
Diketahui insulin dapat menstimulasi sistem saraf simpatis yang memiliki efek peningkatan denyut nadi dan vasokontriksi. Selain itu insulin memiliki efek langsung ke ginjal untuk mestimulasi retensi garam. ${ }^{20}$ Obesitas juga mengaktivasi sistem Renin Angiotensin Aldosteron Sistem (RAAS), karena produksi angiotensinogen salah satunya pada jaringan adiposa. Hal ini akan memicu pembentukan angiotensi II dan aldosteron yang menimbulkan efek vasokontriksi dan retensi cairan dan menyebabkan hipertensi. ${ }^{20,21}$

\section{KESIMPULAN DAN SARAN}

Berdasarkan penelitian ini dapat disimpulkan adanya hubungan antara obesitas dengan hipertensi pada perempuan etnis Minangkabau. Perempuan etnis Minangkabau yang mengalami kejadian hipertensi rata-rata IMT sebesar 32,82 Kg/m2

\section{UCAPAN TERIMA KASIH}

Ucapan terimakasih diberikan kepada seluruh staff Puskesmas anak air yang telah membantu dalam proses pelaksanaan penelitian.

\section{DAFTAR PUSTAKA}

1. Mills KT, Stefanescu A, He J. The global epidemiology of hypertension. Nat Rev Nephrol. 2020;16(4):223-37.

2. Kemenkes RI. Hasil Utama Riset Kesehatan Dasar 2018. Kementrian Kesehat Republik Indones. 2018;

3. Dinas Kesehatan Kota Padang. Pencegahan dan Pengendalian Penyakit Menular. Lap Tah 2018. 2019;135-6.

4. Putra TR. The Effects Of Obesity In The Blood Pressure Elevation. J Major. 2015;4(3).

5. Lu SC, Akanji AO. Leptin, obesity, and hypertension: A review of pathogenetic mechanisms. Metab Syndr Relat Disord. 2020;18(9):399-405.

6. Jalal F, Liputo NI, Susanti N, Oenzil F. Lingkar pinggang, kadar glukosa darah, trigliserida dan tekanan darah pada etnis Minang di Kabupaten Padang Pariaman, Sumatera Barat. Media Med Indones. 2009;43(3):129-36.

7. Sumbar D. Dinas Kesehatan Provinsi Sumatera Barat. 2018. Profil Kesehat Sumatera Barat. 2017;

8. Arum YTG. Hipertensi pada penduduk usia produktif (15-64 tahun). HIGEIA (Journal 
Public Heal Res Dev. 2019;3(3):345-56.

9. Sangadji NW, Nurhayati. Hipertensi Pada Pramudi Bus Transjakarta Di Pt. Bianglala Metropolitan Tahun 2013. Berk Ilm Mhs Kesehat Masy Indones. 2014;2(2):10-7.

10. Masyarakat JK. Hubungan Kebiasaan Konsumsi Masakan Padang Dengan Kadar Kolesterol (Studi Pada Paguyuban Ikatan Mahasiswa Minang Angkatan 2015 Di Semarang). J Kesehat Masy. 2017;5(4):729_ 36.

11. Fitriani E. Pola kebiasaan makan orang lanjut usia (studi kasus: penderita penyakit hipertensi sukubangsa minangkabau di jakarta). Humanus. 2012;11(2):134-44.

12. Astuti VW, Tasman T, Amri LF. Prevalensi Dan Analisis Faktor Risiko Hipertensi Di Wilayah Kerja Puskesmas Nanggalo Padang. BIMIKI (Berkala Ilm Mhs Ilmu Keperawatan Indones. 2021;9(1):1-9.

13. Sulastri D, Elmatris E, Ramadhani R. Hubungan Obesitas Dengan Kejadian Hipertensi Pada Masyarakat Etnik Minangkabau Di Kota Padang. Maj Kedokt Andalas. 2012;36(2):188.

14. Putri DUP, Prasetyo MI, Djamil A. Hubungan Obesitas, Stres Dengan Kejadian Hipertensi Pada Usia Dewasa Muda Di Wilayah Puskesmas Sumbersari Kota Metro. Malahayati Nurs J. 2020;2(4):75869.

15. Solihati S, Ruswanti R. Obesitas dengan Kejadian Hipertensi Pada Mahasiswa Baru Universitas Indonesia Tahun 2013 dan 2014. J Ilm Ilmu Keperawatan Indones. 2018;8(01):388-93.

16. Natalia D, Hasibuan $P$, Hendro $H$. Hubungan Obesitas dengan Hipertensi pada Penduduk Kecamatan Sintang, Kalimantan Barat. eJournal Kedokt Indones. 2015;

17. Rahma G, Gusrianti G. Hubungan Obesitas Sentral Dengan Hipertensi pada Penduduk Usia 25-65 Tahun. JIK (JURNAL ILMU KESEHATAN). 2019;3(2):118-22.

18. Chooi YC, Ding C, Magkos F. The epidemiology of obesity. Metabolism. 2019;92:6-10.

19. Riskesdas. Provinsi Sumatera Barat Riskesdas 2018. Laporan Riskesdas Nasional 2018. 2018. 493 p.

20. Landsberg L, Aronne LJ, Beilin LJ, Burke V, Igel LI, Lloyd-Jones D, et al. ObesityRelated Hypertension: Pathogenesis, Cardiovascular Risk, and Treatment: A Position Paper of The Obesity Society and the American Society of Hypertension Landsberg et al. Obesity Related Hypertension. J Clin Hypertens. 2013;15(1):14-33.

21. Rahmouni K. Obesity-associated hypertension: Recent progress in deciphering the pathogenesis. Hypertension. 2014;64(2):215-21. 